\title{
HIGHER EDUCATION ADVOCACY: THE INTERFACE OF TWO CULTURES
}

\author{
Kim A. Wilcox \\ Executive Director \\ Kansas Board of Regents
}

After spending nearly three years in state government, I still think of myself as an academic. Sometimes, in fact, being in Topeka I feel like Gulliver in a strange land.

The differences and similarities in culture between higher education and the legislature can be seen in many different arenas. For example, in academe, we develop independent lines of research, but we all believe in the value of collaboration in pursuing our research goals. Legislators value independence, as well. In fact their very success in politics is predicated on convincing the electorate that they are independent thinkers and are unique from all other candidates for the position. At the same time, legislators can't get anything done without collaboration. They must be able to build coalitions and implement group goals. Like ours, the legislative merit system is highly individualized (elections) but the day-to-day working mode is collaborative. Their method of collaboration, however, is different from ours. We try to preserve the collegial environment at all cost. For us, compromise means allowing people to follow their own agendas even if we don't agree with what they are doing. In the legislature, compromise means developing a coalition, negotiating a middle ground, and closing a deal to accomplish a short-term goal; the long-term environment is less important

For scientists, peer review is the highest level of accountability. From the outside, this can look self-serving, in that we are essentially reviewing ourselves. Moreover, while we realize that some politics are in play in any human system —including scientific peer review — we trust that the basic process is an objective one. For others, and especially for politicians, it is easy to assume that the politics of the process are much more important in determining the outcome.

Legislators think academics are smart, and they value our knowledge. At the same time, they don't think we're grounded in the real world. Our work is often driven by a variety of goals and motivations that may not be apparent to the public and particularly to members of the public who are focused on local or regional concerns. Legislators also think we don't listen very well. From their perspective, after long conversations about our work and their aspirations for the state and for our science, we go back to our labs and do what we've been doing for years. For us, those conversations were more background and context for a career of science; for them, the same conversations were a request (or perhaps even a demand) for specific activity. 
One of the most fundamental differences between the research community and the legislature is the role of data. Much of the decision-making in the legislature is driven by anecdotes. An anecdote that is replicated a couple of times may prompt us to begin a series of experiments. By contrast, it may prompt the legislature to invoke a law. This difference is driven in large measure by the different timelines on which we operate. In Kansas, 125 of our legislators are elected every two years. As a result, they need "to do something" in Year One, in order to run for re-election in Year Two. They can't wait for several years to test every hypothesis and divine the preferred strategy for achieving particular goals.

Leadership is another area where the legislative and academic cultures differ. On campus, committee chairs are seen as facilitators (and report writers). They are not empowered to determine the agenda, or the direction of the deliberations. For example, there would be an uprising if a faculty committee chair failed to hold a meeting of her/his committee. By contrast, in the legislature, if a chair doesn't want to hold a meeting, the committee doesn't meet. Legislative leadership is crucial in every sense of the word: how an item is discussed, whether it is discussed, and whether there is action.

While not claiming to be an expert, I would offer some advice to the academy in working with the legislature. First we need to provide a focused message. As academics, we tend to seek out complexity. We must realize, however, that the press doesn't deal well with complexity. As a result, our public message too often is lost or confused. We need to spend more time thinking about what it is we are doing and how our work can be cast into an appropriate form. When I was full-time at the university and someone would ask what I did, I would go on at great length trying to describe my applied work in experimental phonetics. My wife would frequently remind me to find a better way to describe my research, because most listeners were yawning before I got to the good part. Generally, people want to know what it is we are going to fix and how long it will take to fix it. This is not how we're used to talking in academia, but we can become better at it.

We can also do a better job of unifying our voices. Too often, we find ourselves espousing our own individual needs and positions. Legislators are not going to give money to one professor versus another or to one department versus another. Instead, they are going to allocate a lump sum to higher education. The extent to which higher education delivers a single message makes it easier for the press to espouse it and easier for the legislature to accomplish our objectives. Too often faculty members are talking about one thing and administrators another. Or, a department advocates one objective, and another department advocates something else. This is healthy in an academic sense, but the more consistent we are in our message, the better we will ultimately fare in the legislative process. 
Our long-term work with legislators should combine "friend-raising" with fund-raising. The faculty can play an important role in this, especially in the "friend-raising" area. Professors can put a human face on what we do, not as advocates, but in telling legislators about their work. What we do is interesting, and it is a source of pride to legislators. We should capitalize on that opportunity. By contrast, almost anything faculty do in asking for funding looks self-serving. That message generally is better carried by the administration, with the faculty's role being to stay in tune with the administration's message.

Anthropologists will tell you that any cultural generalization is just that, a generalization, and shouldn't be construed as definitive particularly in analyzing a given situation. My comments should be taken in that light. They are generalizations derived from my observations over a couple of years. Nonetheless, I hope that they have some utility for you. 